\title{
Метод уменьшения ширины диаграммы направленности InGaAs/GaAs/AIGaAs многоямного гетеролазера
}

\author{
() Н.В. Байдусь*+, С.М. Некоркин*, Д.А. Колпаков*+, А.В. Ершов ${ }^{*+}$, В.Я. Алешкин ${ }^{\bullet+}$, \\ А.А. Дубинов ${ }^{\bullet}$, А.А. Афроненко \\ * Научно-исследовательский физико-технический институт \\ Нижегородского государственного университета им. Н.И. Лобачевского, \\ 603950 Нижний Новгород, Россия \\ - Институт фиизики микроструктур Российской академии наук, \\ 603950 Нижний Новгород, Россия \\ ${ }^{+}$Нижегородский государственный университет им. Н.И. Лобачевского, \\ 603950 Нижний Новгород, Россия \\ - Белорусский государственный университет, \\ 220030 Минск, Республика Беларусь \\ E-mail: kolpdm@gmail.com
}

(Получена 27 апреля 2016 г. Принята к печати 10 мая 2016 г.)

Создан полупроводниковый лазер с оригинальным волноводом, позволяющим добиться существенного обужения диаграммы направленности (до $4^{\circ}$ в плоскости, перпендикулярной $p-n$-переходу). В использованном волноводе, благодаря подбору толщины ограничительных слоев $\mathrm{Al}_{0.3} \mathrm{Ga}_{0.7} \mathrm{As}$, обеспечивается минимальное превышение эффективного показателя преломления возбуждаемой моды $n_{\text {eff }}$ над показателем преломления подложки $n_{\mathrm{s}}\left(n_{\mathrm{eff}}-n_{\mathrm{s}} \ll 1\right)$, что существенно увеличивает размер волноводной моды и приводит к обужению диаграммы направленности.

\section{1. Введение}

Диаграмма направленности типичных полупроводниковых лазеров обычно имеет угловые размеры около $10^{\circ}$ в параллельной и $40^{\circ}$ в перпендикулярной $p-n$-переходу плоскостях, такая форма диаграммы направленности часто требует дополнительной фокусировки для практических применений. Существуют разновидности лазерных диодов, конструкция которых способствует обужению диаграммы направленности, среди которых можно выделить лазеры с широкими и сверхширокими волноводами [1-3], с туннельно-связанными пассивными волноводами $[4,5]$, с выходом излучения через подложку [6,7] и с асимметричной волноводной областью $[8,9]$.

Применение широких и сверхшироких волноводов позволяет получить достаточно высокую мощность полупроводниковых лазеров, однако увеличение ширины волновода ухудшает модовую селективность структуры и способствует появлению волноводных мод высокого порядка. Одной из разновидностей лазеров со сверхшироким волноводом являются лазеры с волноводным эффектом квантовых ям (КЯ) [3]. Волноводы таких лазеров обладают отличной модовой селективностью, однако из-за небольшого фактора оптического ограничения пороговые плотности тока в таких лазерах велики.

В лазерах с туннельно-связанными пассивными волноводами или с асимметричной волноводной областью требуется выращивать достаточно толстые слои с большой точностью из-за большой чувствительности распределения генерируемой моды в лазере к толщине и составу слоев [5]. В лазерах с вытеканием излучения в подложку можно добиться сверхузкой диаграммы направленности, однако эти лазеры обладают большим пороговым током и заметным поглощением излучения в легированной подложке, что требует использования в них многоямной активной области для компенсации потерь [7].

В данной работе приводится результат исследования лазера с оригинальным волноводом, который сочетает в себе преимущества лазеров с асимметричной волноводной областью, с вытеканием излучения в подложку, а также с волноводным эффектом КЯ. За счет такой комбинации этот лазер избавлен от необходимости роста достаточно толстых слоев и от значительного поглощения излучения в легированной подложке. Такая конструкция обеспечивает обужение диаграммы направленности многоямного гетеролазера, а также позволяет добиться значительной мощности излучения в импульсном режиме работы.

\section{2. Конструкция лазерных диодов}

Гетероструктуры, на основе которых созданы образцы лазерных диодов, были выращены методом МОСгидридной эпитаксии при пониженном давлении на установке AIX 200RF. Температура роста варьировалась в диапазоне от $750^{\circ} \mathrm{C}$ (рост ограничительного слоя $\mathrm{Al}_{0.3} \mathrm{Ga}_{0.7} \mathrm{As}$, граничащего с подложкой) до $650^{\circ} \mathrm{C}$ (рост активной области).

Для обеспечения незначительного превышения эффективного показателя преломления фундаментальной $\mathrm{TE}_{0}$-моды над показателем преломления подложки в качестве активной среды в лазере использованы пять InGaAs KЯ, показатель преломления которых больше, чем у GaAs. Кроме того, толстый (1.49 мкм) волноводный слой $\mathrm{GaAs}$, содержащий КЯ, легирован слабее, чем подложка, а ограничительный слой $\mathrm{AlGaAs,} \mathrm{граничащий}$ 
Параметры лазерной гетероструктуры

\begin{tabular}{|c|c|c|c|c|}
\hline \multicolumn{2}{|c|}{ № слоя } & $\begin{array}{c}\text { Состав } \\
\text { слоя }\end{array}$ & $\begin{array}{l}\text { Толщина } \\
\text { слоя, нм }\end{array}$ & $\begin{array}{c}\text { Уровень } \\
\text { легирования слоя, } \mathrm{cm}^{-3}\end{array}$ \\
\hline & 1 & GaAs:Si & 500 & $2 \cdot 10^{18}$ \\
\hline & 2 & $\mathrm{AlGaAs}: \mathrm{Si}$ & 100 & $5 \cdot 10^{17}$ \\
\hline & 3 & GaAs: $\mathrm{Si}$ & 300 & $5 \cdot 10^{16}$ \\
\hline & 4 & GaAs & 50 & \\
\hline 5 & 4 & InGaAs & 10 & \\
\hline 6 & периода & GaAs & 185 & \\
\hline & 13 & InGaAs & 10 & \\
\hline & 14 & GaAs & 50 & \\
\hline & 15 & GaAs:C & 300 & $5 \cdot 10^{16}$ \\
\hline & 16 & AlGaAs: C & 1000 & $2 \cdot 10^{18}$ \\
\hline & 17 & GaAs: C & 300 & $2 \cdot 10^{19}$ \\
\hline
\end{tabular}

с подложкой, достаточно тонок (100 нм). В результате фундаментальная $\mathrm{TE}_{0}$-мода частично выходит в подложку, что равнозначно увеличению апертуры лазерного диода в плоскости, перпендикулярной $p-n$-переходу, пропорционально глубине проникновения поля в подложку. Вследствие этого мы можем наблюдать существенное обужение диаграммы направленности, обусловленное увеличением выходной апертуры волновода. Кроме того, малая разница показателей преломления моды и подложки приводит к существованию только одной локализованной поперечной моды. Послойная конструкция исследуемой гетероструктуры приведена в таблице.

Из структуры AlGaAs/GaAs/InGaAs методами травления, ионной имплантации и напыления диэлектрика изготовлены полупроводниковые лазеры полосковой геометрии с шириной активной области 360 мкм и длинами резонатора $L=1,0.8$ и 0.65 мм. На свежесколотые торцы резонаторов методом электронно-лучевого испарения нанесены интерференционные покрытия с высоким $(R=99 \%)$ и малым $(R=2 \%)$ коэффициентами отражения. Лазеры монтировались на стандартные теплоотводы ТО-18. Измерения в допороговом режиме работы лазера проводились при непрерывной токовой накачке, а в послепороговом режиме была использована импульсная накачка с частотой 1.43 кГц.

\section{3. Результаты исследования и обсуждение}

На рис. 1 показана вычисленная методом матриц переноса зависимость величины электрического поля в фундаментальной $\mathrm{TE}_{0}$-моде от координаты роста структуры для трех значений разницы показателя преломления возбуждаемой моды $n_{\mathrm{eff}}$ и показателя преломления подложки $n_{\mathrm{s}}: \Delta n=n_{\mathrm{eff}}-n_{\mathrm{s}}$. Также на рис. 1 изображена зависимость показателя преломления от координаты. Фундаментальная мода локализуется между ограничительными слоями в волноводной части структуры, при этом толщина нижнего ограничительного слоя на порядок меньше толщины верхнего, за счет чего часть моды проникает в подложку на глубину до 15 мкм. Из рис. 1 видно, что чем меньше $\Delta n$, тем глубже проникает поле в подложку.

Экспериментальным подтверждением данного предположения является ближнепольный снимок излучения передней грани лазера, приведенный на рис. 2. Ближнепольный снимок был сделан при помощи двух выпуклых линз, экрана и цифровой фотокамеры. Торец лазера, работающего в импульсном режиме $(I=40 \mathrm{~A}$, $t_{p}=4$ мкс), был установлен на фокусном расстоянии от первой линзы, вторая линза проецировала изображение грани на экран, изображение с которого было снято на цифровую камеру. Светлая горизонтальная полоса на рис. 2 соответствует излучению, выходящему из волноводной части структуры, что соответствует пику на рис. 1; свечение сверху свидетельствует о наличии излучения, проникающего в подложку и выходящего из нее перпендикулярно передней грани лазера, что

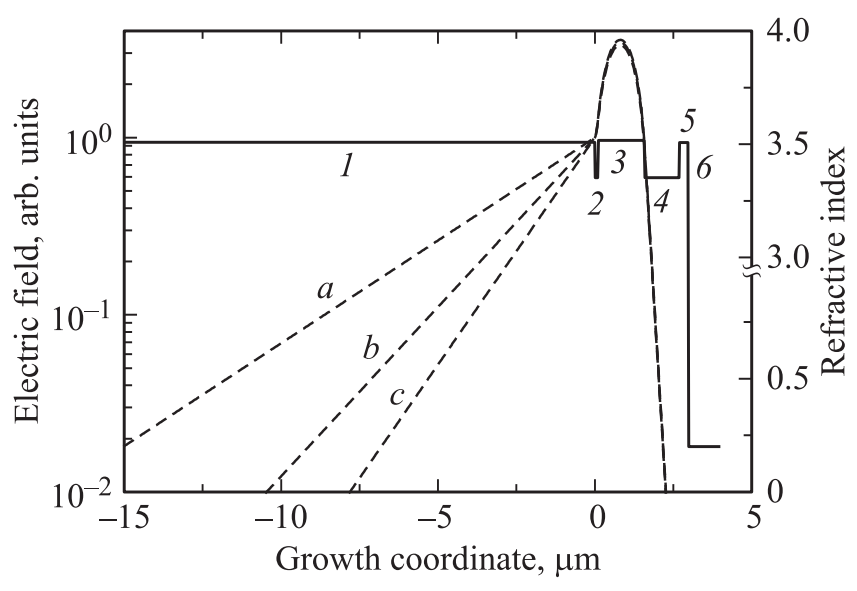

Рис. 1. Расчетная зависимость показателя преломления (сплошная линия) и величины электрического поля в фундаментальной $\mathrm{TE}_{0}$-моде (штриховые кривые) от координаты роста структуры для трех значений скачка показателя преломления $\Delta n: 0(a), 0.0006(b)$ и $0.0011(c)$. Состав слоев: GaAs $(1,3,5), \operatorname{AlGaAs}(2,4), \mathrm{Au}(6)$.



Рис. 2. Ближнепольный снимок излучения передней грани лазера, работающего в импульсном режиме $(I=40 \mathrm{~A}$, $\left.t_{p}=4 \mathrm{M \kappa c}\right)$. 


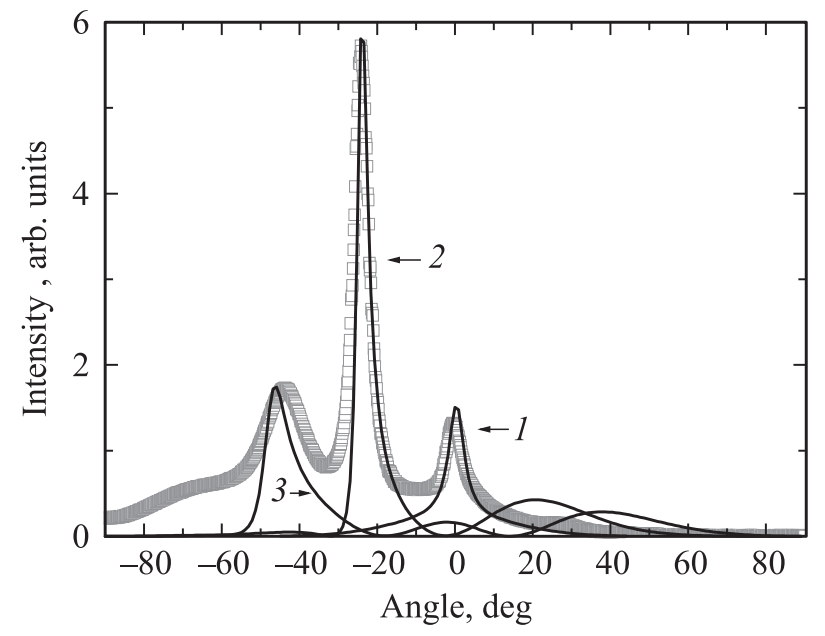

Pис. 3. Диаграммы направленности излучения рассматриваемых лазеров в плоскости, перпендикулярной $p-n$-переходу для трех мод: $\mathrm{TE}_{0}$ (1), $\mathrm{TE}_{1}$ (2) и $\mathrm{TE}_{2}$ (3), вычисленных теоретически для $\Delta n=0$, и экспериментальная диаграмма направленности, измеренная в допороговом режиме для лазера с $L=1 \mathrm{Mм}, I=3 \mathrm{~A}$ (квадраты).

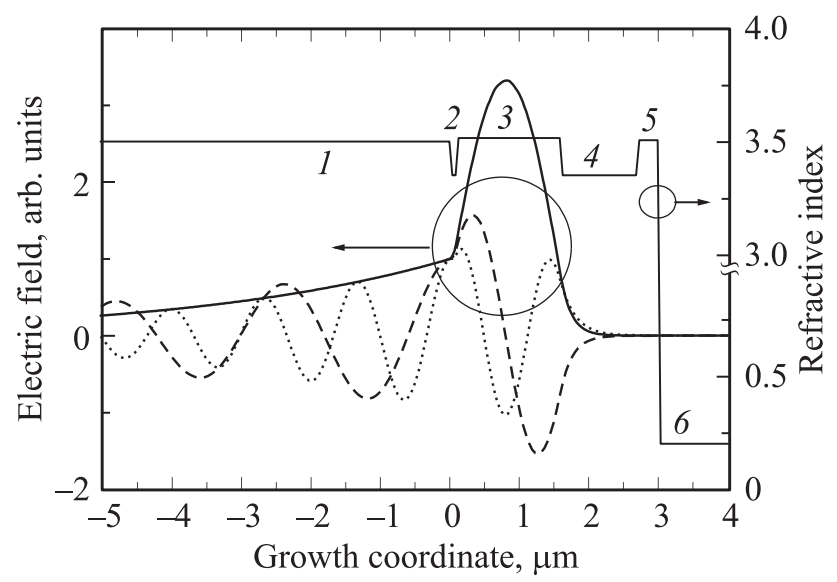

Рис. 4. Расчетная зависимость показателя преломления и электрического поля в $\mathrm{TE}_{0}$ (сплошная кривая), $\mathrm{TE}_{1}$ (штриховая кривая) и $\mathrm{TE}_{2}$ (пунктирная кривая) модах от координаты роста структуры для $\Delta n=0$. Состав слоев: $\operatorname{GaAs}(1,3,5)$, AlGaAs $(2,4), \mathrm{Au}(6)$.

соответствует части вытекающего в подложку излучения на рис. 1.

В ходе исследования диаграммы направленности лазерных диодов в плоскости перпендикулярной слоям $p-n$-перехода, была выявлена тенденция к обужению пика обратно пропорционально длине резонатора: при токе накачки $I=50$ А (импульсный режим, $f_{p}=1.43$ кГц, $t_{p}=180 \mathrm{нc}$ ) ширина пика диаграммы направленности на полувысоте в среднем составила 15,9 и $4^{\circ}$ для образцов с длинами резонатора $1,0.8$ и 0.65 мм соответственно. Стоит отметить, что в допороговом режиме работы лазерного диода диаграмма направленности имеет два дополнительных лепестка, которые свидетельствуют о выходе части излучения через подложку под углами 23 и $43^{\circ}$ к передней грани резонатора (см. рис. 3). Это означает, что работа лазерного диода в допороговом режиме схожа с принципами функционирования лазерных диодов с выходом излучения через подложку [10], когда эффективный показатель преломления возбуждаемых мод меньше показателя преломления подложки $\left(n_{\mathrm{eff}}<n_{\mathrm{s}}\right)$. В этом случае наблюдается спонтанное излучение не только в локализованной фундаментальной $\mathrm{TE}_{0}$-моде (угол выхода $\sim 0^{\circ}$ ), но и в вытекающих в подложку $\mathrm{Te}_{1}$ $\left(23^{\circ}\right)$ и $\mathrm{TE}_{2}\left(43^{\circ}\right)$ модах. Это подтверждается расчетом диаграмм направленности (рис. 3), сделанным в модели, описанной в книге [11], для электрических полей в указанных выше ТЕ-модах (см. рис. 4).

На вставке к рис. 5 представлен типичный спектр излучения лазера в послепороговом режиме. У всех образцов в послепороговом режиме диаграмма направленности имеет только один пик с максимумом около $0^{\circ}$ (см. рис. 5). Этот пик имеет тенденцию к незначительному уширению с ростом тока накачки. Эти факты свидетельствуют о том, что в лазерном диоде такой конструкции в послепороговом режиме с ростом тока накачки происходит локальный разогрев активной области, приводящий к увеличению показателя преломления в области КЯ, а следовательно, к увеличению $n_{\text {eff }}[12]$. Этот же механизм позволяет объяснить зависимость ширины диаграммы направленности от длины резонатора: в более длинных резонаторах, вероятно, разогрев сильнее, поэтому сильнее и локализация моды. Отметим, что ширина диаграммы направленности в лазерном диоде с длиной резонатора 0.65 мм почти на порядок уже, чем у типичного полупроводникового лазера [13] (см. рис. 5).

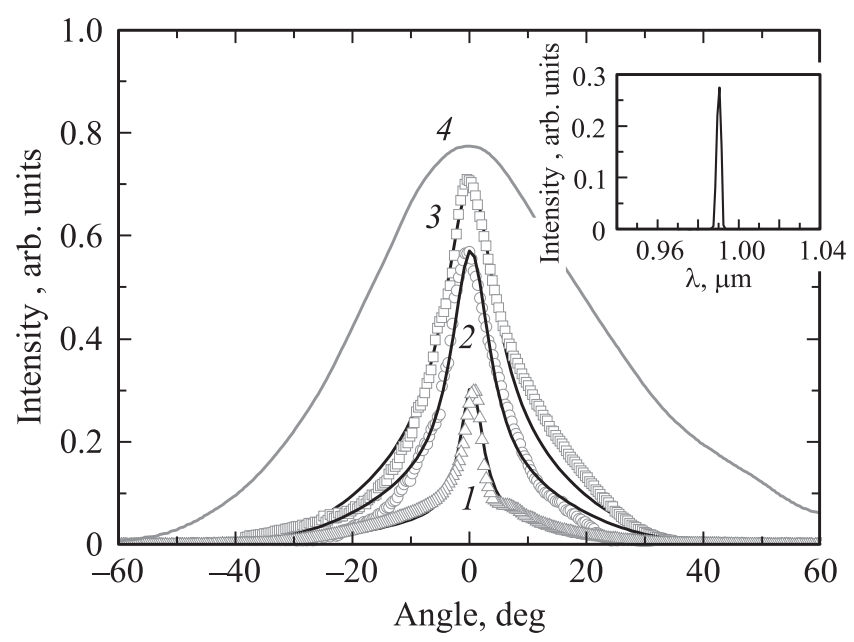

Рис. 5. Диаграммы направленности излучения рассматриваемых лазеров в плоскости, перпендикулярной $p-n$-переходу для трех значений $\Delta n: 0(1), 0.0006$ (2) и 0.0011 (3), вычисленных теоретически и измеренных экспериментально: треугольники $-L=0.65 \mathrm{мм}, I=50 \mathrm{~A}$; кружки $-L=0.8 \mathrm{мм}, I=3 \mathrm{~A}$; квадраты $-L=0.8 \mathrm{мм}, I=50$ А. Номером (4) обозначена диаграмма направленности обычного лазера с шириной волноводного слоя 0.85 мкм (из работы [13]). На вставке - спектр излучения лазера с $L=0.8$ мм и $I=10$ А. 




Рис. 6. Зависимость пиковой мощности излучения (1) и кпд (2) от тока накачки для лазерного диода с $L=1 \mathrm{Mм}$ (импульсный режим, $f_{p}=1.43$ кГц, $t_{p}=180$ нс).

На рис. 6 приведена зависимость пиковой выходной оптической мощности излучения и кпд лазера от тока; кпд определялся как отношение выходной оптической мощности к подводимой электрической мощности [14]. Ниже порога кпд близок к нулю. Выше порогового тока кпд резко возрастает вследствие возникновения лазерного излучения. При больших токах электрическая мощность растет пропорционально квадрату тока, тогда как оптическая - пропорциональна первой степени тока, поэтому кпд падает с ростом тока в режиме больших мощностей. В ходе исследований выявлено, что наибольшая мощность излучения (более 35 Вт при 50 А) достигается у образцов с длиной резонатора 1 мМ. Максимально достигнутое значение кпд составило $36 \%$ при токе накачки $20 \mathrm{~A}$ (рис. 6).

\section{4. Заключение}

Проведенное исследование показало, что предложенная конструкция гетеролазера, совмещая в себе преимущества различных видов волноводов, позволяет достичь малой расходимости излучения в перпендикулярной $p-n$-переходу плоскости, и за счет оригинальной конструкции волновода этот лазер избавлен как от необходимости роста достаточно толстых слоев, так и от значительного поглощения излучения в легированной подложке. Кроме того, лазерные диоды данной конструкции позволяют достигнуть значительной выходной мощности в импульсном режиме работы.

Работа выполнена при поддержке РФФИ-БРФФИ (проект 16-52-00049) и Министерства образования и науки РФ (государственное задание 3.285.2014/К).

\section{Список литературы}

[1] A. Pietrzak, P. Crump, H. Wenzel, G. Erbert, F. Bugge, G. Tränkle. IEEE J. Select. Top. Quant. Electron., 17, 1715 (2011).
[2] С.О. Слипченко, А.А. Подоскин, Д.А. Винокуров, А.Д. Бондарев, В.А. Капитонов, Н.А. Пихтин, П.С. Копьев, И.С. Тарасов. ФТП, 47 (8), 1082 (2013).

[3] В.Я. Алешкин, Н.В. Дикарева, А.А. Дубинов, Б.Н. Звонков, М.В. Карзанова, К.Е. Кудрявцев, С.М. Некоркин, А.Н. Яблонский. Квант. электроню, 43 (5), 401 (2013).

[4] И.А. Авруцкий, Е.М. Дианов, Б.Н. Звонков, Н.Б. Звонков, И.Г. Малкина, Г.А. Максимов, Е.А. Ускова. Квант. электрон., 24 (2), 123 (1997).

[5] И.В. Самарцев, В.Я. Алешкин, Н.В. Дикарева, А.А. Дубинов, Б.Н. Звонков, Д.А. Колпаков, С.М. Некоркин. ФТП, 49 (12), 1625 (2015).

[6] D.R. Scrifers, W. Streifer, R.D. Burnham. Appl. Phys. Lett., 29, 23 (1976).

[7] В.Я. Алешкин, Т.С. Бабушкина, А.А. Бирюков, А.А. Дубинов, Б.Н. Звонков, М.Н. Колесников, С.М. Некоркин. Квант. электрон., 40 (10), 855 (2010).

[8] B.S. Ryvkin, E.A. Avrutin. J. Appl. Phys., 98, 026107 (2005).

[9] В.А. Геловани, А.П. Скороходов, В.И. Швейкин. Высокомощные диодные лазеры нового типа (M., URSS: КомКнига, 2005).

[10] С.М. Некоркин, Б.Н. Звонков, М.В. Карзанова, Н.В. Дикарева, В.Я. Алешкин, А.А. Дубинов. Квант. электрон., $42(10), 931$ (2012).

[11] Х. Кейси, М. Паниш. Лазеры на гетероструктурах (М., Мир, 1981).

[12] А.П. Богатов, А.Е. Дракин, А.А. Лях, А.А. Стратоников, Квант. электрон., 31 (10), 847 (2001).

[13] Н.В. Дикарева, С.М. Некоркин, Б.Н. Звонков, В.Я. Алешкин, А.А. Дубинов, Квант. электрон., 45 (3), 204 (2015).

[14] А.Е. Жуков. Лазеры на основе полупроводниковых структур (СПб., Элмор, 2007).

Редактор А.Н. Смирнов

\section{Decreasing width of directivity diagram for multiwell InGaAs/GaAs/AIGaAs heterolaser}

N.V. Baydus*+, S.M. Nekorkin*, D.A. Kolpakov*+, A.V. Ershov ${ }^{*+}$. V.Ya. Alesjkin ${ }^{\bullet+}$, A.A. Dubinov ${ }^{\bullet+}$, A.A. Afonenko -

* Physicotechnical Research Institute of Lobachevsky State University of Nizhny Novgorod, 603950 Nizhny Novgorod, Russia

- Institute for Physics of Microstructures Russian Academy of Sciences, 603950 Nizhny Novgorod, Russia

- Belorussian State University, 220030 Minsk, Belarus

Abstract A semiconductor laser with original waveguide is developed. It allows to achieve a significant narrowing of the directivity diagram (up to $4^{\circ}$ in the plane perpendicular to the $p-n$-junction). Due to the selection of the thickness of the $\mathrm{Al}_{0.3} \mathrm{Ga}_{0.7} \mathrm{As}$ emitter layers, minimum excess of effective refractive index of excited mode $\left(n_{\text {eff }}\right)$ over the sucstrae refractive index $n_{\mathrm{s}}\left(n_{\mathrm{eff}}-n_{\mathrm{s}} \ll 1\right)$, which significantly increases the size of the waveguide mode and it leads to arrowing of the directivity diagram. 